\title{
Manufacturing Cycle Time Analysis and Scheduling to Optimize Its Duration
}

\author{
Jelena R. Jovanovic 1,2,3,* - Dragan D. Milanovic ${ }^{2}$ - Radisav D. Djukic1,3 \\ 1 Technical College of Applied Studies, Cacak, Serbia \\ 2 University of Belgrade, Faculty of Mechanical Engineering, Serbia \\ 3 'Sloboda' Company, Serbia
}

This paper reports the results of investigations on manufacturing cycle times for special-purpose products. The company performs serial production characterized by complex and diverse technologies, alternative solutions and combined modes of workpiece movement in the manufacturing process. Because of various approaches to this problem, an analysis of previous investigations has been carried out, and a theoretical base is provided for the technological cycle and factors affecting the manufacturing cycle time. The technological and production documentation of the company has been analysed to establish the technological and real manufacturing cycle times, total losses and flow coefficients. This paper describes the original approach to production cycle scheduling on the grounds of investigations of manufacturing capacity utilization levels and causes of loss, in order to measure their effects and to reduce the flow coefficient to an optimum level. The results are a segment of complex studies on the production cycle management of complex products, accomplished in the company in the period from 2010 to 2012.

Keywords: manufacturing cycle, manufacturing capacity utilization level, production losses, material flow, serial production

\section{INTRODUCTION AND PREVIOUS INVESTIGATIONS}

Inherent to the investigation of the manufacturing cycle time is a set of activities, from defining the optimum production lot, calculations of the quantity of required parts, production preparation and launching, cycle scheduling, management of production activities with current asset engagement, to the analysis and investigations of material flow.

Systems for the production of weaponry and military equipment (special-purpose products) have specific positions and roles. Production is regulated by special legal provisions, whereby business operations, among other things, are determined by the product choice and quality, manufacturing, financial and human resources, serial production, complex and diverse technologies, short-term deliveries (as a rule), demands for modification of standard product versions, possibilities to supply specific materials and parts, high-level security during the production, handling, storage and utilization of means.

The start-to-finish treatment cycle implies the choice of benchmark points within which time flows. In terms of production management, the manufacturing cycle determines the duration of business and production activities needed to carry out the overall manufacturing process of a certain quantity of product with minimum time flow, maximum utilization of manufacturing capacity and optimal engagement of financial resources.

Production planning and management is a complex set of activities, as confirmed by many works dealing with this problem [1] to [2]. Eckert and Clarkson [3] describe current planning practice in the development processes for complex industrial products and the challenges associated with it, making suggestions for its improvement. Since they view planning as a project, they emphasize that in order to reduce the duration of project the overlap between tasks must be optimized. In contrast, Alfieri et al. [4] observe the manufacturing-to-order system producing complex items as a set of activities whereby a project scheduling approach should be applied to production planning. They have developed two mathematical models for the execution of activities, i.e. their overlap with a smaller number of activities (up to 30 and up to 60 respectively). Dossenbach [5] analyses the possibility of reducing manufacturing cycle times in the wood-processing industry.

In his work [6], Johnson provides a framework for reducing manufacturing throughput time. It is based on identifying the factors that affect manufacturing throughput time, the actions that can be taken to diminish their impact, and their interactions. The framework is sufficiently detailed to provide guidance to the industry practitioner on how to reduce throughput time, but is sufficiently general to be applied in most manufacturing situations.

Lati and Gilad [7] have developed an algorithm for reducing losses in the semiconductor industry, called the MinBIT (minimizing bottleneck idle time) algorithm, which represents a new method for sequencing the handler's moves; the authors also highlight its application in other industries to bring 
about cycle time reductions and throughput increases. Hermann and Chincholkar [8] describe a decision support tool that can help a product development team to reduce manufacturing cycle time as early as in the product design phase. The design for production (DFP) tool determines how manufacturing a new product design affects the performance of the manufacturing system, taking into account the capacities available and estimating the manufacturing cycle time.

Bottleneck control in real time production [9], prioritizing machine fleet preventive maintenance [10], spare parts inventory for maintenance, optimization of initial buffer adjustment [11], reduction of machine setup time [12] and predicting order lead times [13], can lead to production effects improvement and manufacturing cycle time reduction.

Ko et al. [14] investigate the possibility of reducing cycle times in mass production by input and service rate smoothing.

Based on the analysis of cited works, the following can be concluded:

- A generally accepted approach is to use the flow coefficient as a measure of the manufacturing process efficiency, which rests upon the comparison between the accomplished and technological (ideal) values of the manufacturing cycle.

- Investigations most commonly focus on the cycle within the framework of one-off and smallscale production, where technological values are determined in terms of the consecutive mode of workpiece movement and large-scale and mass production, and where technological values are determined in terms of parallel moves (analysis involves takt time and technological line productivity).

- The technological cycle duration, under conditions of serial production characterized by discontinuity, is calculated using the formulas for the consecutive or parallel mode of workpiece move, depending on the size of the production lot and the author's assessments.

In terms of theoretical considerations and industrial practice, it is of crucial importance to master the key parameters that affect the manufacturing cycle duration under the conditions of complex-product serial production with dominating interruptible processes conditioned by complex and diverse technologies. The manufacturing process includes highly productive machines, having standard and specialized applications, with high concentrations of technological operations, but also the universaltype equipment with expressed differentiation of operations. The technological procedure embraces both productive and non-productive operations with the involvement of technologies used to change the workpiece shape and features.

All the aforementioned manufacturing conditions require an integrated approach in investigating the manufacturing cycle that should enable its permanent reduction through dynamic and cyclic process oriented to:

- generating an exact theoretical framework for calculating the technological cycle duration based on a combined mode of organizing the sequence of technological operations,

- identifying the causes of losses, measuring their effects on manufacturing capacity utilization level and cycle duration,

- manufacturing cycle design with scheduled losses that are lower than planned, taking into account the optimal overlap of activities, and

- production launching, analysing and measuring the manufacturing process efficiency based on a comparison of real and designed values.

Based on all the above-mentioned factors, it can be inferred that cycle time duration is a stochastic quantity directly affected by:

1. factors related to product development and production program (e.g. total number, types, quantities and product complexity),

2. manufacturing capacity of the system and manufacturing process automotive level (e.g. human resources, equipment, space),

3. financial potentials (e.g. current assets, input inventories, size and structure of unfinished production),

4. technologies applied and manufacturing equipment layout (e.g. workplaces),

5. volume of production and modes of workpiece move in the manufacturing process (e.g. optimum production lot, type of production),

6. factors related to the adopted principles of manufacturing and informatics support in all material flow phases,

7. methods applied in production planning, monitoring and management, and

8. causes of cycle losses.

Total manufacturing cycle time (Fig. 1) is a highly complex quantity composed of a range of components, measurable and non-measurable, to be identified, whose conditionality and behaviour regularity has to be established. Cycle time duration consists of productive and non-productive time. Productive time is defined by technological operations related to changes in the workpiece's shape and property, while 
non-productive time involves operations related to transport and control.

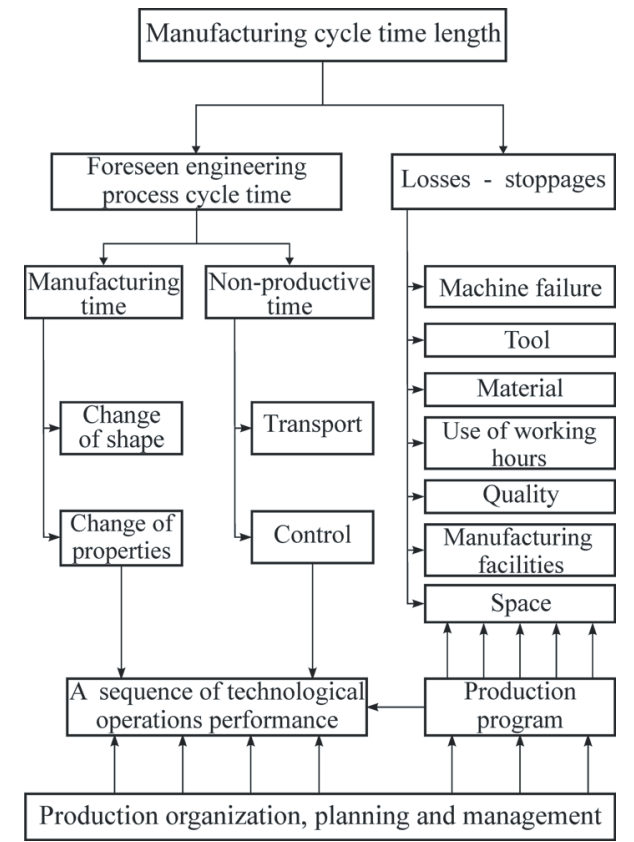

Fig. 1. Several factors on manufacturing cycle time duration

The exposition of the investigation results will be organized into three sections treating:

- Theoretical and technological bases for technological (ideal) manufacturing cycle time scheduling, depending on the mode of organizing the sequence of operations, with investigation results.

- Investigation of real manufacturing cycle time duration, manufacturing capacity utilization level (machines, human resources in manufacturing) and causes of losses.

- Manufacturing cycle scheduling of a chosen product, production launching according to the designed model and investigations of the flow coefficient $K$ based on a comparison of realized and designed states in the production process $\left(K_{p}\right)$, i.e. in terms of comparisons between real and technological (ideal) cycles $\left(K_{t}\right)$ calculated using formulas for combined modes of workpiece movements.

\section{TECHNOLOGICAL (IDEAL) MANUFACTURING CYCLE}

The production program of the plant $P$, Eq. (1), consists of products $X_{j}$ and parts $x_{i}$. The process of parts manufacturing is defined by a set of data $A$ composed of the number of technological operations $n$, ordered set $\theta_{n}$ of times per operation $t_{i}$ and lot size $q$, Eq. (2). Technological manufacturing cycle $T_{t}$, which is also an ideal cycle $T_{c i}$, Eq. (3), includes the time needed for performing all $n$ operations predicted by the technological procedure, on the products of a single lot. Production organization plays a critical role in determining the technological cycle, in which moves may be consecutive $T_{t}^{(u)}$ (Eq. (4)), parallel $T_{t}^{(p)}$ (Eq. (5)) and combined $T_{t}^{(k)}$ (Eqs. (6) or (7)), depending on the type of production, consist of a complex set of features.

$$
\begin{aligned}
& P=\left\{\left(X_{j}, x_{i}\right) \mid j, i \in N\right\}, \\
& x_{i}: A=\left\{n, \theta_{n}, q\right\}, \quad \theta_{n}=\left\{t_{i} \mid i=\overline{1, n}\right\}, \\
& T_{t}=T_{c i}=\left\{T_{t}^{(p)}, T_{t}^{(k)}, T_{t}^{(u)}\right\}, \quad T_{t}^{(p)} \leq T_{t}^{(k)}<T_{t}^{(u)}, \\
& T_{t}^{(u)}=\frac{q \cdot \sum_{i=1}^{n} t_{i}}{H}, \quad\left(\forall x_{i} \mid i=\overline{1, m}\right) \in P \wedge A=\left\{n, \theta_{n}, q\right\}, \\
& T_{t}^{(p)}=\frac{\sum_{i=1}^{n} t_{i}+(q-1) \cdot t_{\max }}{H}, t_{\max }=\max \left\{t_{i} \mid i=\overline{1, n}\right\}, \\
& \left(\forall x_{i} \mid i=\overline{1, m}\right) \in P \wedge A=\left\{n, \theta_{n}, q\right\}, \\
& T_{t}^{(k)}=\frac{\sum_{i=1}^{n} t_{i}+(q-1) \cdot\left(\sum_{k} t_{k}-\sum_{j} t_{j}\right)}{H}, \\
& \left(t_{k-1}<t_{k} \geq t_{k+1} \forall k=\overline{1, n}\right) \wedge\left(t_{j-1} \geq t_{j}<t_{j+1} \forall j=\overline{2, n-1}\right), \\
& \left(\forall x_{i} \mid i=\overline{1, m}\right) \in P \wedge A=\left\{n, \theta_{n}, q\right\}, \\
& T_{t}^{(k)}=\frac{\sum_{i=1}^{n} t_{i}+(q-1) \cdot \sum_{i=1}^{n}\left(t_{i}-t_{i-1}\right) \cdot F_{i}}{H}, \\
& t_{i}>t_{i-1} \Rightarrow F_{i}=1 \wedge t_{i} \leq t_{i-1} \Rightarrow F_{i}=0 \wedge t_{0}=0, \\
& \left(\forall x_{i} \mid i=\overline{1, m}\right) \in P \wedge A=\left\{n, \theta_{n}, q\right\} .
\end{aligned}
$$

Depending on the time units in which the cycle time duration is expressed, the values of parameter $H$ are determined by Eqs. (8) to (11).

$$
\begin{gathered}
H=1 \rightarrow T_{t}[\text { norm hours } / \text { lot }], \\
H=C_{S} \rightarrow T_{t}[\text { shift/lot }], \\
H=C_{S} \cdot S_{d} \rightarrow T_{t}[\text { workdays } / \text { lot }], \\
H=C_{s} \cdot S_{d} \cdot \frac{1}{\delta}, \quad \delta=\frac{D_{k}}{D_{r}} \rightarrow T_{t}[\text { calendar days } / \text { lot }],
\end{gathered}
$$


where:

$t_{i}$ total time per technological operation in norm hour/piece,

$C_{s}$ effective working hours in a shift,

$S_{d}$ number of shifts per day,

$D_{k}$ total number of calendar days in a corresponding period of time,

$D_{r}$ total number of workdays in a corresponding period of time,

$t_{\max }$ run-time length of the longest technological operation,

$t_{k}, t_{j}$ technological operations that satisfy the condition from Eq. (6),

$F_{i}$ a constant that takes the value of 1 or 0 ,

$\delta \quad$ calendar and workdays ratio.

The combined type of work flow in a manufacturing process is most often encountered in serial production. Its goal is to eliminate downtimes emerging at some workplaces (operations) of a parallel type due to the different durations of successive operations, Fig. 2.

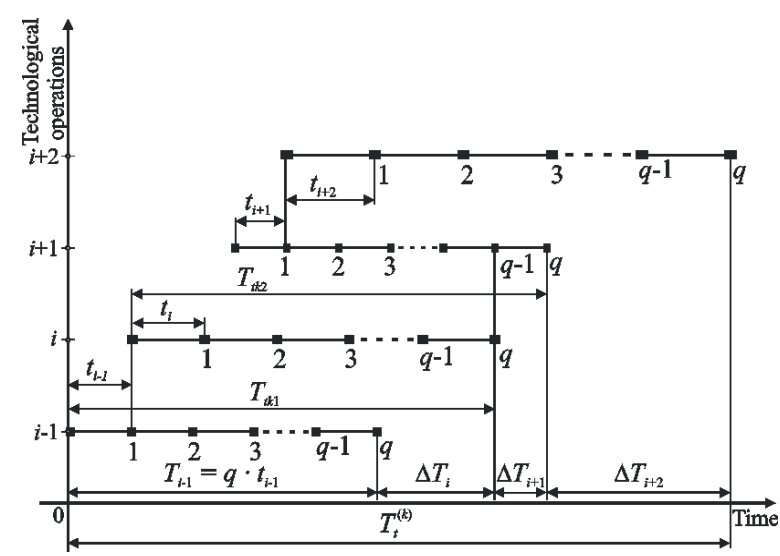

Fig. 2. Graphic representation of a combined mode of workpiece move in the manufacturing process

Table 1. Sequence of technological operations with norms and technological cycle values for a job order lot of $q=30,000$ pieces, in calendar days

\begin{tabular}{|c|c|c|c|c|c|c|c|c|}
\hline \multirow{2}{*}{ 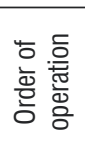 } & \multirow{2}{*}{ 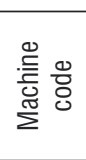 } & \multirow{2}{*}{$\begin{array}{l}\text { Capacity in a } \\
\text { shift } q_{S_{i}} \\
\text { [piece/shift] }\end{array}$} & \multirow{2}{*}{$\begin{array}{c}\text { Time per } \\
\text { operation } \\
\quad t_{i} \\
\text { [cmh/piece] }\end{array}$} & \multicolumn{5}{|c|}{ Parameters for technological cycle calculations } \\
\hline & & & & $t_{\max }$ & $t_{k}$ & $t_{j}$ & $F_{i}$ & $\left(t_{i}-t_{i-1}\right) \cdot F_{i}$ \\
\hline 1 & 2 & 3 & 4 & 5 & 6 & 7 & 8 & 9 \\
\hline 1 & - & 125000 & 6 & - & - & - & 1 & 6 \\
\hline 2 & $M_{1}$ & 18750 & 40 & - & 40 & - & 1 & 34 \\
\hline 3 & - & 93750 & 8 & - & - & 8 & 0 & - \\
\hline 4 & $M_{2}$ & 5600 & 134 & - & 134 & - & 1 & 126 \\
\hline 5 & - & 93750 & 8 & - & - & 8 & 0 & - \\
\hline 6 & $M_{1}$ & 18750 & 40 & - & 40 & - & 1 & 32 \\
\hline 7 & - & 93750 & 8 & - & - & 8 & 0 & - \\
\hline 8 & $M_{3}$ & 4300 & 172 & - & 172 & - & 1 & 164 \\
\hline 9 & - & 93750 & 8 & - & - & 8 & 0 & - \\
\hline 10 & $\mathrm{M}_{4}$ & 18750 & 40 & - & 40 & - & 1 & 32 \\
\hline 11 & - & 93750 & 8 & - & - & 8 & 0 & - \\
\hline 12 & $M_{5}$ & 4300 & 172 & - & 172 & - & 1 & 164 \\
\hline 13 & $M_{6}$ & 4300 & 172 & - & - & 172 & 0 & - \\
\hline 14 & $M_{7}$ & 2500 & 300 & 300 & 300 & - & 1 & 128 \\
\hline 15 & - & 93750 & 8 & - & - & 8 & 0 & - \\
\hline 16 & - & 15000 & 50 & - & - & - & 1 & 42 \\
\hline 17 & - & 8200 & 92 & - & 92 & - & 1 & 42 \\
\hline 18 & $M_{8}$ & 18750 & 40 & - & - & 40 & 0 & - \\
\hline 19 & - & 8200 & 92 & - & 92 & - & 1 & 52 \\
\hline 20 & $\mathrm{M}_{9}$ & 25000 & 30 & - & - & 30 & 0 & - \\
\hline 21 & - & 8200 & 92 & - & 92 & - & 1 & 62 \\
\hline \multirow[t]{4}{*}{22} & - & 375000 & 2 & - & - & - & 0 & - \\
\hline & $\Sigma$ & & 1522 & - & 1174 & 290 & - & 884 \\
\hline & \multicolumn{8}{|c|}{$H=C_{s} \cdot S_{d} \cdot \frac{1}{\delta}=7.5 \cdot 1.3 \cdot 0.704=6.866, \quad \delta=\frac{D k}{D r}=\frac{365}{257}=1.42$} \\
\hline & \multicolumn{8}{|c|}{$T_{t}^{(u)}=66.50 \approx 67$ [cal. days/lot], $T_{t}^{(p)}=13.11 \approx 14$ [cal. days/lot], $T_{t}^{(k)}=38.62 \approx 39$ [cal. days/lot] } \\
\hline
\end{tabular}




\subsection{Calculations of Technological Cycle for an Analysed Product}

The analysed product is manufactured in three displaced organizational units: 1120, 1170 and 1630 . The manufacturing process engages nine different machines $\left(M_{1}\right.$ to $\left.M_{9}\right)$. Ten types of technology are applied, arranged into four groups: heat treatment (one type of technology), mechanical processing/ deformation, cutting (five types of technologies), chemical preparation (two types of technologies) and surface finish (two types of technologies). Of 22 technological operations, 17 are manufacturing (six operations are related to change in shape, 11 to change of characteristics) and five operations are nonmanufacturing (four operations refer to control, one to transport). The total time needed to produce a single part amounts to 0.017 norm hours. The norm structure is composed of $20 \%$ machine time (only a machine is operating), 59\% combined time (both a handler and a machine are operating simultaneously) and $21 \%$ manual time (only handlers are engaged).

On the grounds of technological procedure and Eqs. (4) to (11) for a job order lot of 30,000 parts, Table 1 shows data needed for calculations of the technological cycle as well as the cycle values for consecutive, parallel and combined modes of workpiece movement, Eq. (12). Technological cycle $T_{t}^{(k)}$ is 2.95 times longer than $T_{t}^{(p)}$ and by 1.72 times shorter than $T_{t}^{(u)}$, respectively.

The obtained results confirm the correctness of the approach in which the flow coefficient $K_{t}$ is defined as a real to technological $T_{t}^{(k)}$ ratio instead of $T_{t}^{(u)}$ or $T_{t}^{(p)}$ as has been the practice to date.

$$
T_{t}^{(p)} \cong 14<T_{t}^{(k)} \cong 39<T_{t}^{(u)} \cong 67 .
$$

\section{ANALYSIS OF CYCLE TIME AND CAUSES OF LOSSES IN MANUFACTURING CAPACITY}

Technological cycle $T_{t}$ is an ideal manufacturing cycle $T_{c i}$ because the corresponding Eqs. (4) to (11) do not include losses in the cycle that are unavoidable in the manufacturing process. Unlike technological, cycle time, real duration $T_{c s}$ includes all generated losses $G_{c s}$. Methods for data collecting on manufacturing cycle time duration $T_{c s}$ can be arranged into three groups.

The first group of methods is based on the analysis of manufacturing, planning and other documentation for the system, when it is possible to establish the start and end dates for the manufacturing process. The most commonly used manufacturing documentation items are job order documents (term cards, material requisition, worksheets, delivery notes, etc.), documents of technical control and various reports on the current state of the manufacturing process. For the processes that are rarely repeated, e.g. performed once a year or once in six months, planning documentation and other documents are used, relating to supply, reception, storage and sales for the approximate definition of benchmark points.

The second group of methods includes those based on the measurement of cycle time duration and its components. The chrono-metering method is applied for shorter cycle time durations, while the method of current observations is used for longer cycle time durations that are frequently repeated. Cycle time duration is measured on a representative sample of parts.

The third group is based on estimating the total duration of cycle times. These methods are applied for cases in which the above methods are not applicable or require much effort.

\subsection{Real Cycle, Losses in the Cycle and Flow Coefficient}

The analysis of manufacturing documentation (term cards and reports on the current state of the manufacturing process) was used to determine cycle time duration $T_{c s}$ for a chosen part based on data about the realized start and end dates of production.

Total losses in the cycle $G_{c s}$ are calculated with the help of Eq. (13) when the technological cycle duration $T_{t}$ is subtracted from the real cycle time duration, paying attention to the type of production. Total losses consist of intra-operational $G_{u o}$ and interoperational $G_{m o}$ losses.

Since the company practices a serial type of production, the total losses in the cycle $G_{c s}$, average losses per operation $\varepsilon$ and flow coefficient $K_{t}$, representing the correlation between real and technological cycle time duration, will be calculated using Eqs. (14) to (16). Various approaches to determining the correlation between real and theoretical cycle time duration can be also found in papers [15] and [16].

$$
\begin{gathered}
G_{c s}=T_{c s}-T_{t}=G_{u o}+G_{m o}, \\
G_{c s}=T_{c s}-T_{t}^{(k)}, \\
\varepsilon=\frac{G_{c s}}{n},
\end{gathered}
$$




$$
K_{t}=\frac{T_{c s}}{T_{t}^{(k)}} .
$$

After the cycle time analysis has been completed, the results are presented in Table 2 and Figs. 3 and 4. A total of 13 job orders, seven in 2010 and six in 2011 for the quantity of 30,000 pieces each year were analysed.

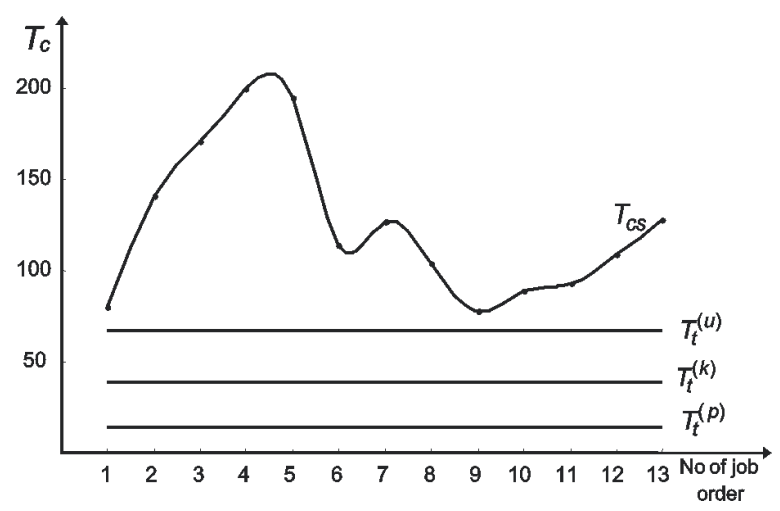

Fig. 3. Technological and real cycle time per job order

Flow coefficient $K_{t}$ (Fig. 4) takes values within 2.02 to 5.18 range. Total losses in the cycle $\left(G_{c s}\right)$ measured against the technological value $T_{t}(k)$ range from 39.4 to 161.4 calendar days, and losses are higher, on average, by 2.24 times than technological cycle duration. Taking into account the parameters from Eq. (17) and the fact that this is a serial repeating production, it can be inferred that the production planning and management process is uncontrollable, experience-based, lacking identified and quantified causes of losses in the cycle.

$$
\begin{gathered}
T_{t}^{(k)}=38.62, \quad 78 \leq T_{c s} \leq 200, \quad 1.8 \leq \varepsilon \leq 7.3, \\
39.4 \leq G_{c s} \leq 161.4, \quad 2.02 \leq K_{t} \leq 5.18 .
\end{gathered}
$$

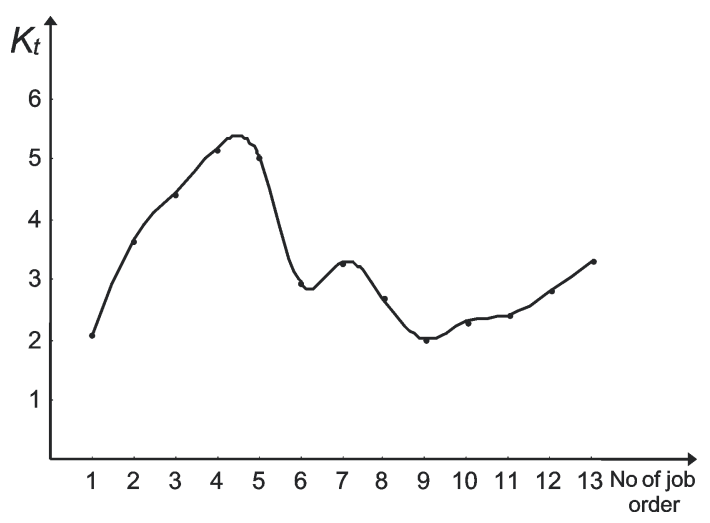

Fig. 4. Flow coefficient $K_{t}$ per job order

\subsection{Utilization of Machine Capacity and Structure of Losses per Cause of Downtime}

Taking into account the obtained results, Eq. (17), and the importance of the analysed product that is on a critical path of the manufacturing cycle of four complex products making up the framework of the 2010 and 2011 production programs, the causes and

\begin{tabular}{|c|c|c|c|c|c|c|c|c|c|}
\hline \multirow{3}{*}{ No } & \multicolumn{4}{|c|}{ Job order (J0) } & \multicolumn{2}{|c|}{ Cycle time duration } & \multicolumn{2}{|c|}{ Losses } & \multirow{3}{*}{$\begin{array}{c}\text { Flow } \\
\text { coefficien } \\
K_{t}\end{array}$} \\
\hline & \multirow{2}{*}{ Lot } & \multirow{2}{*}{ Quantity } & \multicolumn{2}{|c|}{ Manufacturing date } & \multirow{2}{*}{$T_{t}^{(k)}$} & \multirow{2}{*}{$T_{c s}$} & \multirow{2}{*}{$G_{c s}$} & \multirow{2}{*}{$\varepsilon$} & \\
\hline & & & Start & End & & & & & \\
\hline 1 & 2 & 3 & 4 & 5 & 6 & 7 & $8=7-6$ & 9 & $10=7 / 6$ \\
\hline 1 & $04 / 10$ & 30000 & 30.08 .2010 & 17.11 .2010 & \multirow{13}{*}{$\begin{array}{l}\text { ్ָర } \\
\text { ల్ల }\end{array}$} & 80 & 41.4 & 1.9 & 2.07 \\
\hline 2 & $05 / 10$ & 30000 & 30.08 .2010 & 17.01 .2011 & & 141 & 102.4 & 4.7 & 3.65 \\
\hline 3 & $06 / 10$ & 30000 & 30.08 .2010 & 16.02 .2011 & & 171 & 132.4 & 6.0 & 4.43 \\
\hline 4 & $07 / 10$ & 30000 & 30.08 .2010 & 17.03 .2011 & & 200 & 161.4 & 7.3 & 5.18 \\
\hline 5 & $08 / 10$ & 30000 & 18.09 .2010 & 31.03 .2011 & & 195 & 156.4 & 7.1 & 5.05 \\
\hline 6 & $09 / 10$ & 30000 & 16.12 .2010 & 08.04 .2011 & & 114 & 75.4 & 3.4 & 2.95 \\
\hline 7 & $10 / 10$ & 30000 & 16.12 .2010 & 21.04 .2011 & & 127 & 88.4 & 4.0 & 3.29 \\
\hline 8 & $01 / 11$ & 30000 & 23.02 .2011 & 06.06 .2011 & & 104 & 65.4 & 3.0 & 2.69 \\
\hline 9 & $03 / 11$ & 30000 & 09.04 .2011 & 25.06 .2011 & & 78 & 39.4 & 1.8 & 2.02 \\
\hline 10 & $04 / 11$ & 30000 & 09.04 .2011 & 06.07 .2011 & & 89 & 50.4 & 2.3 & 2.30 \\
\hline 11 & $05 / 11$ & 30000 & 07.07 .2011 & 07.10 .2011 & & 93 & 54.4 & 2.5 & 2.41 \\
\hline 12 & $06 / 11$ & 30000 & 07.07 .2011 & 23.10 .2011 & & 109 & 70.4 & 3.2 & 2.82 \\
\hline 13 & $07 / 11$ & 30000 & 08.09 .2011 & 13.01 .2012 & & 128 & 89.4 & 4.1 & 3.31 \\
\hline \multicolumn{5}{|c|}{ Average value: } & & 125.3 & 86.7 & 3.9 & 3.24 \\
\hline
\end{tabular}

Table 2. Real manufacturing cycle time duration $T_{c s}$, total losses in the cycle $G_{c s}$, losses in the cycle per operation $\varepsilon$ and values of flow coefficient $K_{t}$, in calendar days 
measurements of losses were investigated with regard to the manufacturing capacity. The causes of losses (i) were identified (Eq. (18)), and machine capacity utilization level $\eta_{m}$ was established for the operations with machines and combined time cycles (Eq. (19)), with respect to cycle times in the structure of normhour per technological operation. Machine capacity utilization level and current losses, per downtime cause, can be measured with different techniques [17].

$$
\begin{gathered}
g_{m}=\sum_{i=1}^{8} g_{i}, \quad i=\{K, A, M, C, I, V, O, X\}, \\
\eta_{m}=\frac{n(+)}{n}, \quad g_{i}=\frac{n_{i}(-)}{n},
\end{gathered}
$$

where:

$g_{m} \quad$ total losses of machine capacity,

$g_{i} \quad$ machine capacity losses per downtime cause (i),

$n \quad$ total number of observations,

$n(+) \quad$ number of observations when the machine is running,

$n_{i}(-)$ number of observations for machine downtime per downtime cause (i).
In this investigation, the method of current observations (MCO) was employed. The MCO is based on mathematical statistics and sampling theory. To apply the MCO, it is necessary to define the representative sample, choose the time period for screening (e.g. day, month, shift, number of observations required per shift), perform preparations for screening (e.g. train screeners, identify causes of losses, prepare screening sheets, define mode of data recording and processing, screener's route and sequence of screening the machines).

Test screening identified eight causes of losses for machine capacity $(i)$ : machine breakdown $(K)$, tool insufficiency and failure $(A)$, waiting for a workpiece from the preceding operation $(I)$, downtime caused by handler's lack of discipline $(C)$, material shortage $(M)$, waiting for the workpiece from another organizational unit $(V)$, lack of jobs $(X)$ and other causes (e.g. downtimes due to power failure, fluid shortage, strikes) $(O)$. In addition to the abovementioned eight characteristics related to current causes of losses, another two characteristics screened were associated with the operation of machines: machine is operating $(T)$ and preparation-finish jobs $(P)$.

Table 3. Experiment plan for measuring machine capacity utilization level and current losses, using the MCO method, accomplished in 2010

\begin{tabular}{ccccccccccc}
\hline \multirow{2}{*}{ No } & \multirow{2}{*}{ OU } & \multirow{2}{*}{$\begin{array}{c}\text { No of } \\
\text { machines }\end{array}$} & $n_{11}$ & $n_{12}$ & $n_{1}$ & $n_{2}$ & $n_{3}$ & $n^{*}$ & \multicolumn{2}{c}{$\begin{array}{c}\text { No of } \\
\text { features }\end{array}$} \\
\hline 1 & 2 & 3 & 4 & 5 & $6=4+5$ & 7 & 8 & $9=6 \times 7 \times 8$ & $10=3 \times 9$ & 11 \\
\hline 1 & $1120 / I$ & 2 & 20 & 20 & 40 & 10 & 12 & 4800 & 9600 & 10 \\
\hline 2 & 1170 & 4 & 20 & 20 & 40 & 10 & 12 & 4800 & 19200 & 10 \\
\hline 3 & $1120 / / 1$ & 3 & 20 & 20 & 40 & 10 & 12 & 4800 & 14400 & 10 \\
\hline
\end{tabular}

Note: $n_{11}$ no of observations per machine in shift $1, n_{12}$ no of observations per machine in shift $2, n_{1}$ no of observations per machine/day, $n_{2}$ no of screening days per month, $n_{3}$ no of screening months per year, $n^{*}$ total number of observations per machine/year, $m$ total number of observations for all machines per organizational unit

Table 4. Utilization level $\eta_{m}$, total $g_{m}$ and partial losses $g_{i}$ of machine capacity, per cause of downtime and machines, and scheduled

\begin{tabular}{|c|c|c|c|c|c|c|c|c|c|c|c|c|}
\hline \multirow{2}{*}{ No } & \multirow{2}{*}{$M_{i}$} & \multirow{2}{*}{$\eta_{m}$} & \multicolumn{8}{|c|}{ Values of partial losses $g_{i}$, per cause of downtime $(i)$} & \multirow{2}{*}{$g_{m}$} & \multirow{2}{*}{$\mu_{m}$} \\
\hline & & & $g_{M}$ & $g_{A}$ & $g_{K}$ & $g_{C}$ & $g_{X}$ & $g_{I}$ & $g_{V}$ & $g_{O}$ & & \\
\hline 1 & 2 & 3 & 4 & 5 & 6 & 7 & 8 & 9 & 10 & 11 & 12 & $13=3+4+8$ \\
\hline 1 & $\mathrm{M}_{1}$ & 0.4600 & 0.1250 & 0.0200 & 0.1150 & 0.0450 & 0.1800 & 0.0000 & 0.0000 & 0.0550 & 0.5400 & 0.7650 \\
\hline 2 & $\mathrm{M}_{2}$ & 0.5600 & 0.0000 & 0.0250 & 0.0000 & 0.0250 & 0.2150 & 0.1450 & 0.0000 & 0.0300 & 0.4400 & 0.7750 \\
\hline 3 & $M_{3}$ & 0.5350 & 0.0500 & 0.0650 & 0.1450 & 0.0300 & 0.1650 & 0.0000 & 0.0000 & 0.0100 & 0.4650 & 0.7500 \\
\hline 4 & $\mathrm{M}_{4}$ & 0.4500 & 0.0000 & 0.0500 & 0.1050 & 0.0250 & 0.2150 & 0.1400 & 0.0000 & 0.0150 & 0.5500 & 0.6650 \\
\hline 5 & $\mathrm{M}_{5}$ & 0.4900 & 0.0850 & 0.0500 & 0.0400 & 0.0550 & 0.2500 & 0.0000 & 0.0000 & 0.0300 & 0.5100 & 0.8250 \\
\hline 6 & $\mathrm{M}_{6}$ & 0.5150 & 0.1200 & 0.0250 & 0.0150 & 0.0150 & 0.3000 & 0.0000 & 0.0000 & 0.0100 & 0.4850 & 0.9350 \\
\hline 7 & $\mathrm{M}_{7}$ & 0.5600 & 0.0000 & 0.0450 & 0.0750 & 0.0500 & 0.0900 & 0.1350 & 0.0000 & 0.0450 & 0.4400 & 0.6500 \\
\hline 8 & $M_{8}$ & 0.6950 & 0.0000 & 0.0600 & 0.0200 & 0.0900 & 0.0000 & 0.0900 & 0.0000 & 0.0450 & 0.3050 & 0.6950 \\
\hline 9 & $M_{9}$ & 0.3700 & 0.0000 & 0.0050 & 0.1650 & 0.0200 & 0.3850 & 0.0550 & 0.0000 & 0.0000 & 0.6300 & 0.7550 \\
\hline \multicolumn{2}{|c|}{ Average } & 0.5150 & 0.0422 & 0.0383 & 0.0756 & 0.0394 & 0.2000 & 0.0628 & 0.0000 & 0.0267 & 0.4850 & 0.7572 \\
\hline
\end{tabular}
parameters values $\mu_{m}$ 
Table 3 shows the experiment plan, and Table 4 displays the results obtained by the program developed in paper [18]. Table 4 (column 13) shows scheduled values for machine capacity utilization levels $\mu_{m}$, Eq. (20) to be used for scheduling manufacturing cycle time optimum values $T_{c p}$. The scheduled capacity utilization level $\left(\mu_{m}\right)$ is essentially the potential of each of nine engaged machines $\left(M_{i}\right)$. Its value, Relation (20), includes losses caused by material shortages $\left(g_{M}\right)$ and lack of jobs $\left(g_{X}\right)$.

The average machine's utilization engaged in the manufacturing process of an analysed product in 2010 amounts to $51.5 \%$. Individually, per machine, it ranges from 37 to $69.5 \%$ (Table 4 , column 3 ).

$$
\mu_{m}=\eta_{m}+\left(g_{M}+g_{X}\right) .
$$

\subsection{Productive Human Resources Utilization Level and Current Losses per Cause of Working Hour Loss}

The goal of each business-manufacturing system is to have the optimum number of employees $\left(z_{u}\right)$ in both administration $\left(z_{a}\right)$ and production $(z)$. Investigations of the causes for losses in working hours and productive human resources utilization level $\eta_{r}$ are of significance for workplaces and technological operations with prevailing manual work [19].

In order to identify and reveal regularities in causes for working hour losses, corresponding data were collected and analysed in human resources department in the year 2010. The human resources utilization level $\eta_{r}$, Eq. (21), and current losses $\left(\mathrm{z}_{j}\right)$, per cause $(j)$, were established based on handlers' work records. The analysis indicated eight causes of working hour losses (j), Eq. (22): sick leave up to 30 days $\left(b_{1}\right)$, sick leave over 30 days $\left(b_{2}\right)$, unexcused absence from work and tickets out $(i)$, holiday $\left(g_{o}\right)$, downtime (e.g. lack of jobs, strikes, vis major) $\left(p_{r}\right)$, paid and unpaid leave $(o)$, national holidays $\left(d_{p}\right)$, and engagement in other jobs $(d)$. The total number of employed workers $\left(z_{u}\right)$ is the sum of productive $(z)$ and clerical $\left(z_{a}\right)$ workers. The average number of productive workers present at work every day $\left(z_{r}\right)$ is the difference between the total number of productive workers and the average number of productive workers absent from work for all the abovementioned reasons $\left(z_{g}\right)$, Eq. (23). The scheduled norm hours (nh) load per worker $\left(F_{n c}\right)$, coefficient of productive worker overtime engagement $\left(\xi_{r}\right)$ and scheduled productive worker utilization level $\left(\mu_{r}\right)$ can be calculated by employing Eqs. (24) to (26).

$$
\begin{gathered}
\eta_{r}=\frac{z-z_{g}}{z}=\frac{z_{r}}{z}, \\
z_{g}=\sum_{j=1}^{8} z_{j}, \quad j=\left\{b_{1}, b_{2}, i, g_{o}, p_{r}, o, d_{p}, d\right\}, \\
z_{u}=z+z_{a}, \quad z_{r}=z-z_{g}, \\
F_{n c}=D_{r} \cdot C_{s} \cdot p_{n}, \quad p_{n}=\frac{\sum N C}{\sum E C}, \\
\xi_{r}=\frac{z_{r} \cdot F_{n c}+P_{e}}{z_{r} \cdot F_{n c}}, \\
\mu_{r}=\eta_{r} \cdot \xi_{r} .
\end{gathered}
$$

The scheduled norm hours load per worker $\left(F_{n c}\right)$ is obtained as the product of the total number of working days $\left(D_{r}\right)$, effective working hours in a shift

\begin{tabular}{|c|c|c|c|c|c|c|c|c|c|c|c|c|c|c|c|}
\hline \multirow{2}{*}{ N } & \multicolumn{8}{|c|}{$z_{j}, j=\left\{b_{1}, b_{2}, i, g_{o}, d_{p}, p_{r}, o, d\right\}[\%]$} & \multicolumn{2}{|r|}{$z_{g}$} & \multirow{2}{*}{ 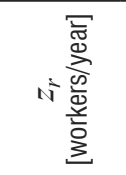 } & \multirow{2}{*}{$\begin{array}{l}\eta_{r} \\
{[\%]}\end{array}$} & \multirow{2}{*}{$\begin{array}{c}P_{e} \\
\text { [nh/ } \\
\text { year] }\end{array}$} & \multirow{2}{*}{$F_{n c}$} & \multirow{2}{*}{$\xi_{r}$} \\
\hline & $z_{b_{1}}$ & $z_{b_{2}}$ & $z_{i}$ & $z_{g_{o}}$ & $z_{d_{p}}$ & $z_{p_{r}}$ & $z_{o}$ & $z_{d}$ & [\%] & $\begin{array}{c}\text { [workers/ } \\
\text { year] }\end{array}$ & & & & & \\
\hline 1 & 2 & 3 & 4 & 5 & 6 & 7 & 8 & 9 & 10 & 11 & $12=1-11$ & 13 & 14 & 15 & 16 \\
\hline 800 & 6.15 & 1.8 & 1.35 & 11.4 & 2.85 & 1.8 & 1.35 & 0.3 & 27 & 216 & 584 & 73 & 163917 & 2217 & 1.13 \\
\hline & & & $\begin{array}{l}=D_{r} \\
=\frac{z_{r}}{} .\end{array}$ & $\begin{array}{l}C_{s} \cdot p \\
{ }_{n c}+P \\
\cdot F_{n c}\end{array}$ & $\begin{array}{l}=25^{\circ} \\
=58\end{array}$ & $\begin{array}{l}7.5 \cdot \\
221^{\prime} \\
584 .\end{array}$ & $\begin{array}{l}15=2 \\
+163 \\
217\end{array}$ & $\begin{array}{l}17[\mathrm{n} \\
\frac{7}{1}=1\end{array}$ & vorke & annually & & & & & \\
\hline
\end{tabular}
$\left(C_{s}\right)$ and the average norm hour [nh] execution $\left(p_{n}\right)$ for the observed organizational unit and a corresponding time period. The average norm-hour is obtained when the executed norm-hours $(N C)$ are divided by the engaged effective working hours $(E C)$ of productive

Table 5. Productive human resources utilization level $\eta_{r}$, total $z_{g}$ and partial $z_{j}$ losses of working hours, and scheduled parameter values $\mu_{r}$ 
workers per worksheet. The coefficient of overtime engagement depends on the specificity of workplaces and planned level of overtime hours $\left(P_{e}\right)$.

Table 5 show parameters relevant to the utilization of productive human resources (PHR). Due to an adverse age structure, working hours losses are high on account of sick leave $\left(b_{1}, b_{2}\right)$ and holiday $\left(g_{o}\right)$. Of the total of 800 workers, $27 \%$ or 216 workers are, on average, absent from work. Productive human resource (PHR) utilization level amounts to $73 \%$. Taking into account the coefficient of overtime engagement $\left(\xi_{r}\right)$, the scheduled utilization level of PHR $\left(\mu_{r}\right)$ equals $82 \%$.

\section{MANUFACTURING CYCLES SCHEDULING}

The optimization of manufacturing cycle times $T_{c p}$ requires, first of all, investigations of losses causes, measurement of their values, minimization of their effects and scheduling of total losses $G_{c p}$ to be lower than made $G_{c s}$, Fig. 5 .

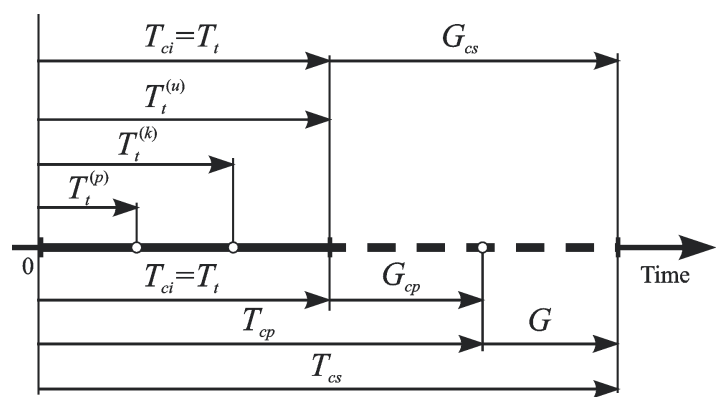

Fig. 5. Technological, scheduled and real manufacturing cycle time duration with corresponding losses

When scheduling the manufacturing cycles, the scheduled cycle duration $T_{c p}$ should tend to the optimum, Fig. 5. In other words, the goal of scheduling as a cyclic process is to permanently tend to the minimization of total losses, which means that scheduled losses $\left(G_{c p}\right)$ should always be less than generated $\left(G_{c s}\right)$ in all optimization steps, Eq. (27).

$$
\begin{gathered}
T_{c p}=T_{t}+G_{c p}, \quad T_{c s}=T_{t}+G_{c s}=T_{c p}+G, \\
T_{t}<T_{c p}<T_{c s} \rightarrow G_{c p}<G_{c s} .
\end{gathered}
$$

The scheduled manufacturing cycle duration $T_{c p}$, Eq. (29), Figs. 6 and 7, aside from productive and non-productive cycle times, predicted by technological procedures, take into account scheduled manufacturing capacity utilization levels $\mu_{i}\left(\mu_{m}, \mu_{r}\right)$, Eqs. (20) and (26), real manufacturing conditions per operation, Eq. (28) and scheduled losses in a cycle $\left(G_{c p}, \Delta \tau\right)$, Eq. (30).

$$
\begin{gathered}
\tau_{i}=\frac{q}{q_{s_{i}} \cdot p_{i} \cdot S_{d_{i}} \cdot \mu_{i} \cdot r_{i}} \cdot \delta, \\
T_{c p}=\tau_{1}+(n-1) \cdot \Delta \tau+\sum_{p}^{k}\left(\tau_{p}-\tau_{p-1}\right), \\
p=i \mid\left(i=\overline{2, n} \wedge \tau_{i}>\tau_{i-1}\right) \rightarrow \sum p=k, \\
\tau_{1}+(n-1) \cdot \Delta \tau+\sum_{p}^{k}\left(\tau_{p}-\tau_{p-1}\right)=T_{t}+G_{c p} \rightarrow \\
\Delta \tau=\frac{T_{t}+G_{c p}-\tau_{1}-\sum_{p}^{k}\left(\tau_{p}-\tau_{p-1}\right)}{n-1},
\end{gathered}
$$

where:

$\tau_{i}$ scheduled duration of technological operations,

$\Delta \tau$ average partial loss between technological operations,

$p$ technological operation satisfying the condition from Eq. (29).

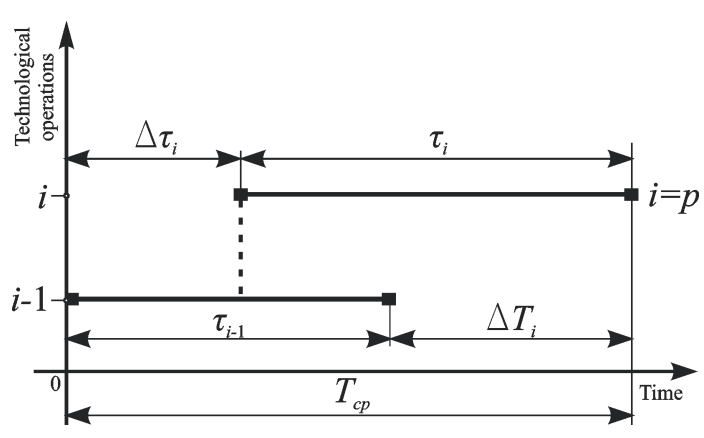

Fig. 6. Scheduled loss $\Delta \tau_{i}, \tau_{i}>\tau_{i-1}$

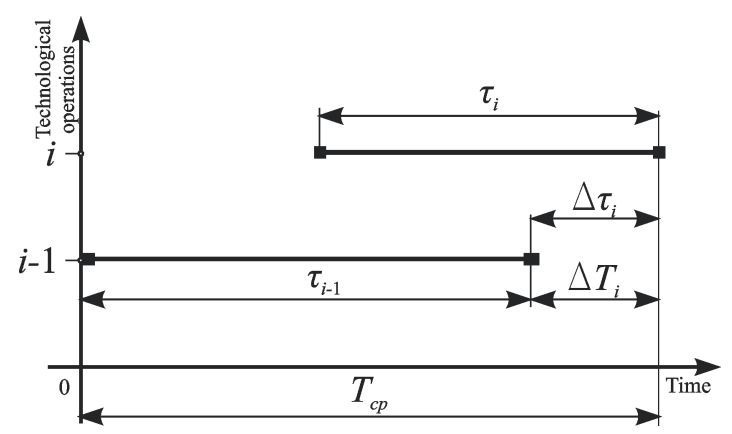

Fig. 7. Scheduled loss $\Delta \tau_{i}, \tau_{i} \leq \tau_{i-1}$

\subsection{Algorithm for Cycle Scheduling}

The first step in the scheduling process is calculating the manufacturing cycle time duration per operation $\left(\tau_{i}\right)$ using Eq. (28), with respect to real manufacturing conditions: the number of workplaces 
per technological operation $\left(r_{i}\right)$, the number of shifts per day $\left(S_{d_{i}}\right)$, the average norm-hour execution $\left(p_{i}\right)$, manufacturing capacity utilization $\mu_{i}\left(\mu_{m}, \mu_{r}\right)$ and the norm-set capacity per shift $\left(q_{S_{i}}\right)$, Table 6 . Inventories in unfinished production and losses due to quality inadequacy are included in calculations via the formulas for planning the quantity $(q)$ of the product to be produced.

Table 6. Parameters for scheduling the manufacturing cycle

\begin{tabular}{|c|c|c|c|c|c|c|c|c|}
\hline 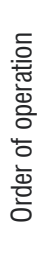 & 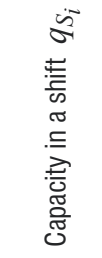 & 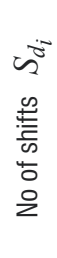 & 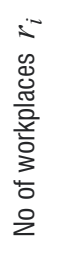 & 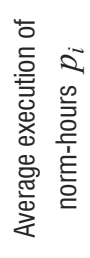 & $\mu_{i}$ & $\tau_{i}$ & 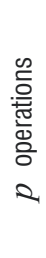 & 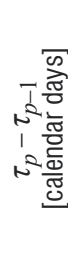 \\
\hline 1 & 2 & 3 & 4 & 5 & 6 & 7 & 8 & 9 \\
\hline 1 & 125000 & 1 & 1 & 1.10 & 0.820 & 0.38 & & \\
\hline 2 & 18750 & 2 & 2 & 1.02 & 0.765 & 0.73 & $\sqrt{ }$ & 0.35 \\
\hline 3 & 93750 & 1 & 1 & 1.08 & 0.820 & 0.51 & & \\
\hline 4 & 5600 & 2 & 3 & 1.04 & 0.775 & 1.57 & $\sqrt{ }$ & 1.06 \\
\hline 5 & 93750 & 1 & 1 & 1.13 & 0.820 & 0.49 & & \\
\hline 6 & 18750 & 2 & 2 & 1.02 & 0.765 & 0.73 & $\sqrt{ }$ & 0.24 \\
\hline 7 & 93750 & 1 & 1 & 1.10 & 0.820 & 0.50 & & \\
\hline 8 & 4300 & 2 & 4 & 1.10 & 0.750 & 1.50 & $\sqrt{ }$ & 1.00 \\
\hline 9 & 93750 & 1 & 1 & 1.09 & 0.820 & 0.51 & & \\
\hline 10 & 18750 & 2 & 2 & 1.06 & 0.665 & 0.81 & $\sqrt{ }$ & 0.30 \\
\hline 11 & 93750 & 1 & 1 & 1.09 & 0.820 & 0.51 & & \\
\hline 12 & 4300 & 2 & 4 & 1.05 & 0.825 & 1.43 & $\sqrt{ }$ & 0.92 \\
\hline 13 & 4300 & 2 & 4 & 1.03 & 0.935 & 1.29 & & \\
\hline 14 & 2500 & 2 & 6 & 1.05 & 0.650 & 2.08 & $\sqrt{ }$ & 0.79 \\
\hline 15 & 93750 & 1 & 1 & 1.13 & 0.820 & 0.49 & & \\
\hline 16 & 15000 & 2 & 2 & 1.15 & 0.820 & 0.75 & $\sqrt{ }$ & 0.26 \\
\hline 17 & 8200 & 1 & 3 & 1.12 & 0.820 & 1.89 & $\sqrt{ }$ & 1.13 \\
\hline 18 & 18750 & 2 & 2 & 1.10 & 0.695 & 0.74 & & \\
\hline 19 & 8200 & 2 & 2 & 1.18 & 0.820 & 1.34 & $\sqrt{ }$ & 0.60 \\
\hline 20 & 25000 & 1 & 1 & 1.07 & 0.755 & 2.11 & $\sqrt{ }$ & 0.77 \\
\hline 21 & 8200 & 1 & 3 & 1.13 & 0.820 & 1.87 & & \\
\hline 22 & 375000 & 1 & 1 & 1.18 & 0.820 & 0.12 & & \\
\hline
\end{tabular}

In the second step, it is necessary to adopt the total losses in the cycle $G_{c p}$, and, then using Eq. (30), to determine average partial losses between technological operations $\Delta \tau$. Total scheduled losses in the cycle should be lower than those average (86.7 calendar days). They can be determined in a number of ways: by the help of Eq. (31) adopting the minimum value of losses in the cycle $G_{c S}$ (Table 2, column 8).

$$
\begin{aligned}
& G_{c p} \leq \min G_{c s}, \quad G_{c p} \leq 39.4 \\
\min G_{c s}= & \min \left\{\begin{array}{lllll}
41.4 & 102.4 & 132.4 & \ldots & 89.4
\end{array}\right\} .
\end{aligned}
$$

The scheduled value of total losses $G_{c p}$ can be also found using Eq. (32).

$$
G_{c p}=T_{c}-T_{t}^{(k)} .
$$

The expected cycle time duration $T_{c}$ will be calculated by applying Eqs. (6) or (7) if the values of the technological times per operation $t_{i}$ (Table 1, column 4) are corrected by the corresponding coefficients $\mu_{i}$ (Table 6, column 6). Data required for calculating the expected values of cycle duration $T_{c}$ are given in Table 7.

According to the investigations [20], total losses in the cycle in the company follow the beta distribution, where the value $G_{c^{\prime}}=M_{o}=15.97$ has the highest probability (modal value).

Based on the above analysis, total loss $G_{c p}$ of 16 calendar days was adopted, and partial loss $\Delta \tau$ was calculated in calendar days, Eq. (33):

$$
\Delta \tau=\frac{T_{t}+G_{c p}-\tau_{1}-\sum_{p}^{k}\left(\tau_{p}-\tau_{p-1}\right)}{n-1}=2.2 .
$$

The third step implies calculating scheduled values for the cycle $T_{c p}$, in calendar days, using data from Table 6 and Eq. (29):

$$
T_{c p}=\tau_{1}+(n-1) \cdot \Delta \tau+\sum_{p}^{k}\left(\tau_{p}-\tau_{p-1}\right)=54
$$

Correlation between real $T_{c s}$ and scheduled $T_{c p}$ manufacturing cycle time duration is determined by the flow coefficient $K_{p}$, Eq. (35).

$$
K_{p}=\frac{T_{c s}}{T_{c p}}
$$

\subsection{Production Launching According to the Scheduled Model and Analysis of Results}

The scheduled mode of manufacturing $\left(T_{c p}\right)$ was realized in two production lots (job order lot 11/11 and 13/11) in 2011 and 2012. In both job order lots, the quantity of 30,000 pieces each was launched. Prior to production initiation, in the 'Term card' document, the scheduled start and end dates for the manufacturing process per operation were recorded (with respect to the results obtained in Section 3.1).

When determining and recording the dates in the 'Term card', it is necessary to calculate temporal reserves between the end and start dates of production 
Table 7. Parameters for calculating expected cycle time duration $T_{c}$

\begin{tabular}{|c|c|c|c|c|c|c|c|c|}
\hline \multirow{2}{*}{$\begin{array}{l}\text { Order of } \\
\text { operation }\end{array}$} & \multirow{2}{*}{$\begin{array}{l}\text { Machine } \\
\text { code }\end{array}$} & \multirow{2}{*}{$\begin{array}{c}\text { Time per } \\
\text { operation } t_{i} \\
\text { [cmh/piece] }\end{array}$} & \multirow[b]{2}{*}{$\mu_{i}$} & \multirow{2}{*}{$\begin{array}{c}\text { Corrected time } \\
\text { per operation } \\
{[\mathrm{cmh} / \text { piece }]}\end{array}$} & \multicolumn{4}{|c|}{ Parameters for calculating technological cycle time } \\
\hline & & & & & $t_{k}$ & $t_{j}$ & $F_{i}$ & $\left(t_{i}-t_{i-1}\right) \cdot F_{i}$ \\
\hline 1 & 2 & 3 & 4 & $5=3 / 4$ & 6 & 7 & 8 & 9 \\
\hline 1 & - & 6 & 0.820 & 7 & - & - & 1 & 7 \\
\hline 2 & $\mathrm{M}_{1}$ & 40 & 0.765 & 52 & 52 & - & 1 & 45 \\
\hline 3 & - & 8 & 0.820 & 10 & - & 10 & 0 & 0 \\
\hline 4 & $\mathrm{M}_{2}$ & 134 & 0.775 & 173 & 173 & - & 1 & 163 \\
\hline 5 & - & 8 & 0.820 & 10 & - & 10 & 0 & 0 \\
\hline 6 & $\mathrm{M}_{1}$ & 40 & 0.765 & 52 & 52 & - & 1 & 42 \\
\hline 7 & - & 8 & 0.820 & 10 & - & 10 & 0 & 0 \\
\hline 8 & $\mathrm{M}_{3}$ & 172 & 0.750 & 229 & 229 & - & 1 & 219 \\
\hline 9 & - & 8 & 0.820 & 10 & - & 10 & 0 & 0 \\
\hline 10 & $\mathrm{M}_{4}$ & 40 & 0.665 & 60 & 60 & - & 1 & 50 \\
\hline 11 & - & 8 & 0.820 & 10 & - & 10 & 0 & 0 \\
\hline 12 & $\mathrm{M}_{5}$ & 172 & 0.825 & 208 & 208 & - & 1 & 198 \\
\hline 13 & $\mathrm{M}_{6}$ & 172 & 0.935 & 184 & - & 184 & 0 & 0 \\
\hline 14 & $\mathrm{M}_{7}$ & 300 & 0.650 & 462 & 462 & - & 1 & 278 \\
\hline 15 & - & 8 & 0.820 & 10 & - & 10 & 0 & 0 \\
\hline 16 & - & 50 & 0.820 & 61 & - & - & 1 & 51 \\
\hline 17 & - & 92 & 0.820 & 112 & 112 & - & 1 & 51 \\
\hline 18 & $\mathrm{M}_{8}$ & 40 & 0.695 & 58 & - & 58 & 0 & 0 \\
\hline 19 & - & 92 & 0.820 & 112 & 112 & - & 1 & 54 \\
\hline 20 & $\mathrm{M}_{9}$ & 30 & 0.755 & 40 & - & 40 & 0 & 0 \\
\hline 21 & - & 92 & 0.820 & 112 & 112 & - & 1 & 72 \\
\hline 22 & - & 2 & 0.820 & 2 & - & - & 0 & 0 \\
\hline \multicolumn{2}{|c|}{$\Sigma$} & 1522 & - & 1984 & 1572 & 342 & - & 1230 \\
\hline
\end{tabular}

Eq. (6) $\rightarrow T_{c}=(1984+29999 \cdot(1572-342)) / 100000 / 6.866=53.74$ [calendar days/lot]

Eq. (32) $\rightarrow G_{c p}=53.74-38.62=15.12 \approx 16$ [calendar days/lot]

Table 8. Parameters of the cycle established after production is finished according to the scheduled model

\begin{tabular}{|c|c|c|c|c|c|c|c|c|}
\hline \multirow{3}{*}{ No } & \multicolumn{4}{|c|}{ Job order } & \multicolumn{2}{|c|}{ Manufacturing cycle } & \multirow{3}{*}{$G$} & \multirow{3}{*}{$K_{p}$} \\
\hline & \multirow{2}{*}{ Lot } & \multirow{2}{*}{ Quantity } & \multicolumn{2}{|c|}{ Date } & \multirow{2}{*}{$T_{c p}$} & \multirow{2}{*}{$T_{c s}$} & & \\
\hline & & & Start & End & & & & \\
\hline 1 & 2 & 3 & 4 & 5 & 6 & 7 & $8=7-6$ & $9=7 / 6$ \\
\hline 1 & $11 / 11$ & \multirow{2}{*}{30000} & 24.10 .2011 & 02.01 .2012 & \multirow{2}{*}{54} & 71 & 17 & 1.31 \\
\hline 2 & $13 / 11$ & & 05.12 .2011 & 03.02 .2012 & & 61 & 7 & 1.13 \\
\hline & & & & & Average value: & 66 & 12 & 1.22 \\
\hline
\end{tabular}

on a current operation. Their value depends on the scheduled partial loss $\Delta \tau$ and organizational mode of production (Figs. 6 and 7). During production activities per technological operation, the start and end dates of production were added to the column denoting scheduled dates.

After production is finished according to the designed model, Table 8 shows realized manufacturing cycle time duration $\left(T_{c S}\right)$, losses in the cycle $(G)$ and values of the flow coefficient $K_{p}$, Relation (35).

Table 9 displays parameters $\left(T_{c s}, G, K_{p}, K_{t}\right)$ for 15 job orders of the analysed part, whose production was realized in the period from 2010 to 2012 . In the first 13 job orders (Nos 1 to 13), the manufacturing cycle was not scheduled; therefore production process management was performed based on experience and priorities defined by operational managers.

The achieved values of the cycle $T_{c s}$ (Table 9, column 5, Nos 14 and 15) are considerably lower than the analysed values of the cycles per job order (Table 9, column 5, Nos 1 to 13). The flow coefficient $K_{p}$ (1.13 to 1.31$)$ takes considerably lower values than the coefficient $K_{t}$ (2.02 to 5.18), which implies that 
Table 9. Values of the flow coefficients $\left(K_{p}, K_{t}\right)$ before and after production launching according to the designed model

\begin{tabular}{|c|c|c|c|c|c|c|c|c|}
\hline \multirow{2}{*}{ No } & \multicolumn{2}{|c|}{ Job order } & \multicolumn{3}{|c|}{ Manufacturing cycle and losses } & \multirow{2}{*}{ Kp } & \multirow{2}{*}{$\mathrm{Kt}$} & \multirow{2}{*}{ Production } \\
\hline & Lot & Quantity & Tcp & Tcs & $G$ & & & \\
\hline 1 & 2 & 3 & 4 & 5 & $6=5-4$ & $7=5 / 4$ & 8 & 9 \\
\hline 1 & $04 / 10$ & \multirow{13}{*}{30000} & \multirow{13}{*}{54} & 80 & 26 & 1.48 & 2.07 & \multirow{13}{*}{$\begin{array}{l}\text { Experience- } \\
\text { based } \\
\text { production }\end{array}$} \\
\hline 2 & $05 / 10$ & & & 141 & 87 & 2.61 & 3.65 & \\
\hline 3 & $06 / 10$ & & & 171 & 117 & 3.17 & 4.43 & \\
\hline 4 & $07 / 10$ & & & 200 & 146 & 3.70 & 5.18 & \\
\hline 5 & $08 / 10$ & & & 195 & 141 & 3.61 & 5.05 & \\
\hline 6 & $09 / 10$ & & & 114 & 60 & 2.11 & 2.95 & \\
\hline 7 & $10 / 10$ & & & 127 & 73 & 2.35 & 3.29 & \\
\hline 8 & $01 / 11$ & & & 104 & 50 & 1.93 & 2.69 & \\
\hline 9 & $03 / 11$ & & & 78 & 24 & 1.44 & 2.02 & \\
\hline 10 & $04 / 11$ & & & 89 & 35 & 1.65 & 2.30 & \\
\hline 11 & $05 / 11$ & & & 93 & 39 & 1.72 & 2.41 & \\
\hline 12 & $06 / 11$ & & & 109 & 55 & 2.02 & 2.82 & \\
\hline 13 & $07 / 11$ & & & 128 & 74 & 2.37 & 3.31 & \\
\hline \multicolumn{4}{|c|}{ Average value: } & 125.3 & 71.3 & 2.32 & 3.24 & \multirow{4}{*}{$\begin{array}{c}\text { Designed } \\
\text { model-based } \\
\text { production }\end{array}$} \\
\hline 14 & $11 / 11$ & \multirow{2}{*}{30000} & \multirow{2}{*}{54} & 71 & 17 & 1.31 & 1.84 & \\
\hline 15 & $13 / 11$ & & & 61 & 7 & 1.13 & 1.58 & \\
\hline \multicolumn{4}{|c|}{ Average value: } & 66 & 12 & 1.22 & 1.71 & \\
\hline
\end{tabular}

the coefficient $K_{p}$ is more suitable for measuring the production process efficiency than the coefficient $K_{t}$.

\section{CONCLUSION AND FURTHER RESEARCH}

The goal of the original approach demonstrated in this work is to reduce manufacturing cycle time to the maximum, taking into account serial production characterized by discontinuity and the considerable amount of current assets needed for financing the production process. This methodology is based on designed models that, on one hand, respect current technical-technological and manufacturing documentation and, on the other, real production constraints. The parameters for reducing manufacturing cycle are flow coefficients $K_{p}$ and $K_{t}$ (Fig. 8).

When measured by flow coefficients $K_{p}$ and $K_{t}$, the average realized manufacturing cycle time duration, according to the designed model, is lower by 1.9 times (Table 9, columns 7 and 8 ), while the average losses in the cycle are smaller by 5.9 times (Table 9, column 6). Viewed from the angle of the manufacturing system, the flow coefficient $K_{p}$ has a higher use value (Eq. (35)), because the accomplished values of the cycle are correlated with scheduled (planned) values. In this context, the model design becomes a cyclical process with the aim of minimizing total losses and reducing them to an optimal (i.e. acceptable) level. However, to compare the results with other business-manufacturing systems, from the region and more distant areas, priority should be given to flow coefficient $K_{t}$, Eq. (16), because the values achieved for the cycle are compared to the technological (ideal) cycle, which is calculated for the case of serial production and combined workpiece move using Eqs. (6) or (7).

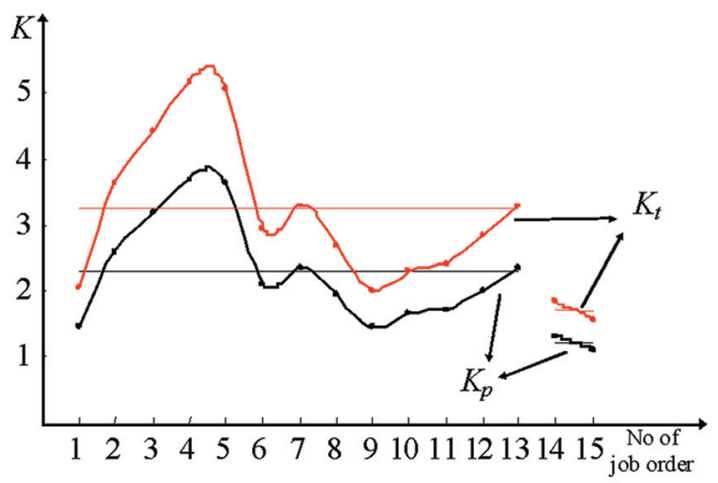

Fig. 8. Values of flow coefficients $K_{p}$ and $K_{t}$ per job order before and after scheduling

The results related to the identification of downtime causes and losses measurement are of importance not only for the cycle scheduling, but also for optimal production planning.

Further research should be directed to the analysis and scheduling of manufacturing cycle for complex products. It is necessary to define models for describing the structures of complex products 
with respect to technological documentation and techniques that allow for the scheduling approach to realization of orders. The designed solutions, that are based on the principles of lean production, should make provisions for software application solutions from the domain of project management.

\section{REFERENCES}

[1] Slak, A., Tavcar, J., Duhovnik, J. (2011). Application of genetic algorithm into multicriteria batch manufacturing scheduling. Strojniški vestnik - Journal of Mechanical Engineering, vol. 57, no. 2, p. 110-124, DOI:10.5545/sv-jme.2010.122.

[2] Suzic, N., Stevanov, B., Cosic, I., Anisic, Z., Sremcev, N. (2012). Customizing products through application of group technology: A case study of furniture manufacturing. Strojniški vestnik - Journal of Mechanical Engineering, vol. 58, no. 12, p. 724-731. DOI:10.5545/sv-jme.2012.708.

[3] Eckert, C., Clarkson, P. (2010). Planning development processes for complex products. Research in Engineering Design, vol. 21, no. 3, p. 153-171, DOI:10.1007/s00163-009-0079-0.

[4] Alfieri, A., Tolio, T., Urgo, M. (2011). A project scheduling approach to production planning with feeding precedence relations. International Journal of Production Research, vol. 49, no. 4, p. 995-1020, DOI:10.1080/00207541003604844.

[5] Dossenbach, T. (2000). Manufacturing cycle time reduction - a must in capital project analysis. Wood \& Wood Products, vol. 105, no. 11, p. 31-35.

[6] Johnson, J.D. (2003). A framework for reducing manufacturing through put time. Journal of Manufacturing Systems, vol. 22, no. 4, p. 283-298, DOI:10.1016/S0278-6125(03)80009-2.

[7] Lati, N., Gilad, I. (2010). Minimising idle times in cluster tools in the semiconductor industry. International Journal of Production Research, vol. 48, no. 21, p. 6443-6459, DOI:10.1080/00207540903280556.

[8] Herrmann, J.W., Chincholkar, M.M. (2000). Design for production: A tool for reducing manufacturing cycle time. Proceedings of the 2000 ASME Design Engineering Technical Conference, Baltimore, from: http://www.isr.umd.edu/Labs/CIM/projects/dfp/ dfm2000.pdf.

[9] Li, L., Chang, Q., Ni, J., Biller, S. (2009). Real time production improvement through bottleneck control. International Journal of Production Research, vol. 47, no. 21, p. 6145-6158, DOI:10.1080/00207540802244240.

[10] Patti, A.L., Watson, K.J. (2010). Downtime variability: the impact of duration-frequency on the performance of serial production systems. International Journal of Production Research, vol. 48, no. 19, p. 5831-5841, DOI:10.1080/00207540903280572.

[11] Schultz, C.R. (2004). Spare parts inventory and cycle time reduction. International Journal of Production Research, vol. 42, no. 4, p. 759-776, DOI:10.1080/0020 7540310001626210.

[12] Kusar, J., Berlec, T., Zefran, F., Starbek, M. (2010). Reduction of machine setup time. Strojniški vestnik Journal of Mechanical Engineering, vol. 56, no. 12, p. 833-845.

[13] Berlec, T., Govekar, E., Grum, J., Potocnik, P., Starbek, M. (2008). Predicting order lead times. Strojniški vestnik - Journal of Mechanical Engineering, vol. 54, no. 5, p. 308-321.

[14] Ko, S.S., Serfozo, R., Sivakumar, A.I. (2004). Reducing cycle times in manufacturing and supply chains by input and service rate smoothing. IIE Transactions, vol. 36, no. 2 , p. 145-153, DOI:10.1080/07408170490245441.

[15] Puich, M. (2001). Are you up to the cycle-time challenge?. IIE Solutions, vol. 33, no. 4, p. 24-28.

[16] Hadas, L., Cyplik, P., Fertsch, M. (2009). Method of buffering critical resources in maketo-order shop floor control in manufacturing complex products. International Journal of Production Research, vol. 47, no. 8, p. 2125-2139, DOI:10.1080/00207540802572582.

[17] Djukic, R., Jovanovic, R.J., Mutavdzic, M. (2009). Investigations of machine capacity utilization level, downtime causes and structure of losses. Proceedings of Jupiter Conference, Belgrade, p. 4.11-4.16. (in Serbian)

[18] Djukic, R., Milanovic, D., Jovanovic, R.J. (2010). Program for establishing machine capacity utilization level. Proceedings of Quality Conference, Kragujevac, from: http://www.cqm.rs/2010/pdf/37/37.pdf. (in Serbian)

[19] Djukic, R., Jovanovic, R.J. (2009). Effects of human resources on dynamic management of manufacturing systems. Proceedings of Jupiter Conference, Belgrade, p. 4.1-4.6. (in Serbian)

[20] Djukic, R. (2010). Dynamic balance and managing of complex business-manufacturing systems. PhD Thesis. University of Belgrade, Belgrade. (in Serbian) 